\title{
Measurement of effective alveolar carbon dioxide tension during spontaneous breathing in normal subjects and patients with chronic airways obstruction
}

\author{
J Jordanoglou, N Koulouris, D Kyroussis, P Rapakoulias, P Vassalos, J Madianos
}

\begin{abstract}
Background - The measurement of effective alveolar carbon dioxide tension (PA$\mathrm{CO}_{2} \mathrm{eff}$ ) is still a matter of debate. It has, however, become common practice to use arterial instead of alveolar $\mathrm{CO}_{2}$ tension for computing alveolar oxygen tension $\left(\mathrm{PAO}_{2}\right)$ and physiological dead space, not only in normal subjects but also in patients. The purpose of this study was to estimate alveolar $\mathrm{CO}_{2}$ tension during spontaneous breathing with a new bedside technique which is simple and non-invasive, and to compare these values with arterial $\mathrm{CO}_{2}$ tension measured in normal subjects and patients with chronic airways obstruction. Methods - The subjects breathed quietly through the equipment assembly (mouthpiece, monitoring ring, Fleisch transducer head) connected to a pneumotachograph and a fast response infrared $\mathrm{CO}_{2}$ analyser. The method is a computerised calculation of the volume weighted effective alveolar $\mathrm{CO}_{2}$ tension obtained from the simultaneously recorded expiratory flow and $\mathrm{CO}_{2}$ concentration versus time curves. An arterial blood sample was taken to measure $\mathrm{PaCO}_{2}$ for comparison during the study.

Results - The results showed a mean difference $\left(\mathrm{PACO}_{2} \mathrm{eff}-\mathrm{PaCO}_{2}\right)$ of $-0.205 \mathrm{kPa}$ in 20 normal subjects and $-0.460 \mathrm{kPa}$ in 46 patients. The $95 \%$ confidence interval of the bias was -0.029 to $-0.379 \mathrm{kPa}$ in normal subjects and -0.213 to $-0.707 \mathrm{kPa}$ in patients. The limits of agreement between $\mathrm{PACO}_{2}$ eff and $\mathrm{PaCO}_{2}$ were 0.526 to -0.935 in normal subjects and 1.170 to $-2 \cdot 088$ in patients.
\end{abstract}

Conclusions - The volume weighted effective alveolar $\mathrm{PCO}_{2}$ in normal subjects and patients with chronic airways obstruction is lower than the arterial $\mathrm{PCO}_{2}$ and is recommended as a better estimate in the classical equations for estimating dead space and intrapulmonary shunt.

(Thorax 1995;50:240-244)

Keywords: alveolar $\mathrm{CO}_{2}$ tension, alveolar-arterial $\mathrm{PCO}_{2}$ difference, chronic airways obstruction, spontaneous breathing.

The estimation of effective alveolar carbon dioxide tension is still a matter of debate because the available methodology is not widely ac- cepted. In most classical calculations alveolar carbon dioxide tension $\left(\mathrm{PACO}_{2}\right)$ has been assumed to be equivalent to arterial blood $\mathrm{CO}_{2}$ tension $\left(\mathrm{PaCO}_{2}\right)$ in normal subjects. ${ }^{1-10}$ It has also become common in clinical practice and in research work to use arterial $\mathrm{CO}_{2}$ tension as a substitute for alveolar $\mathrm{CO}_{2}$ tension for the computation of alveolar oxygen tension $\left(\mathrm{PAO}_{2}\right)$ and of the physiological dead space/tidal volume ratio (VDphys/VT). ${ }^{12568-11}$ The aim of this study was to estimate effective alveolar $\mathrm{CO}_{2}$ tension during tidal breathing with a new and simple technique and to compare these values with arterial $\mathrm{CO}_{2}$ tension in both normal subjects and patients with chronic airways obstruction.

\section{Methods}

THEORETICAL CONSIDERATIONS

The method is based on the computation of the effective $\mathrm{CO}_{2}$ concentration in the expired air at the mouth $\left(\mathrm{FeCO}_{2} \mathrm{eff}\right)$ and the dead space/ tidal volume ratio $(\mathrm{VD} / \mathrm{VT})$ on the $\operatorname{VE} / \mathrm{time}(\mathrm{t})$ curve by the aid of the effective time (teff) of the $\mathrm{FCO}_{2} / \mathrm{t}$ curve. The computed values of $\mathrm{FECO}_{2}$ eff and $\mathrm{VD} / \mathrm{VT}$ are used in Bohr's equation for the estimation of the effective alveolar $\mathrm{CO}_{2}$ concentration per breath $\left(\mathrm{FACO}_{2} \mathrm{eff}\right)$.

The expiratory flow $(\dot{\mathrm{V}} / \mathrm{t})$ and the $\mathrm{CO}_{2}$ concentration versus time $\left(\mathrm{FCO}_{2} / \mathrm{t}\right)$ curves are first aligned for the phase lag $(\Phi)$. This exists between the two curves as a result of the different response times between the pneumotachograph and the capnograph. The $\mathrm{FCO}_{2}$ limits of the $\mathrm{FCO}_{2} / \mathrm{t}$ curve are determined by the points of zero flow on the $\dot{V} \mathrm{E} / \mathrm{t}$ curve - that is, the beginning and the end of expiration. The initial part of the $\mathrm{FCO}_{2} / \mathrm{t}$ curve has zero $\mathrm{FCO}_{2}$ values and variable duration $\left(\mathrm{t}_{0}\right)$. At the end point of $t_{0}$ the rate of rise of $\mathrm{FCO}_{2}\left(\mathrm{dFCO}_{2} / \mathrm{dt}\right)$ is steep, but it decreases progressively until the end of the curve. At this point $\mathrm{FCO}_{2}$ and $\mathrm{FeTCO}_{2}$ are equal (fig 1). In some $\mathrm{FCO}_{2} / \mathrm{t}$ curves the end part of the curve reaches a plateau. The area over the $\mathrm{FCO}_{2} / \mathrm{t}$ curve $\left[\int \mathrm{FCO}_{2} \mathrm{dt}(\mathrm{a})\right]$ is confined by the horizontal line at the level of $\mathrm{FETCO}_{2}$ parallel to the time axis, and the vertical line passing through the end point of the time interval $\left(t_{0}\right)$ (fig 1$)$. The ratio of this area divided by $\mathrm{FETCO}_{2}$ equals the effective time of the curve (teff) (fig 1):

$$
\text { teff }=\int \mathrm{FCO}_{2} \mathrm{dt}(\mathrm{a}) / \mathrm{FETCO}_{2}
$$




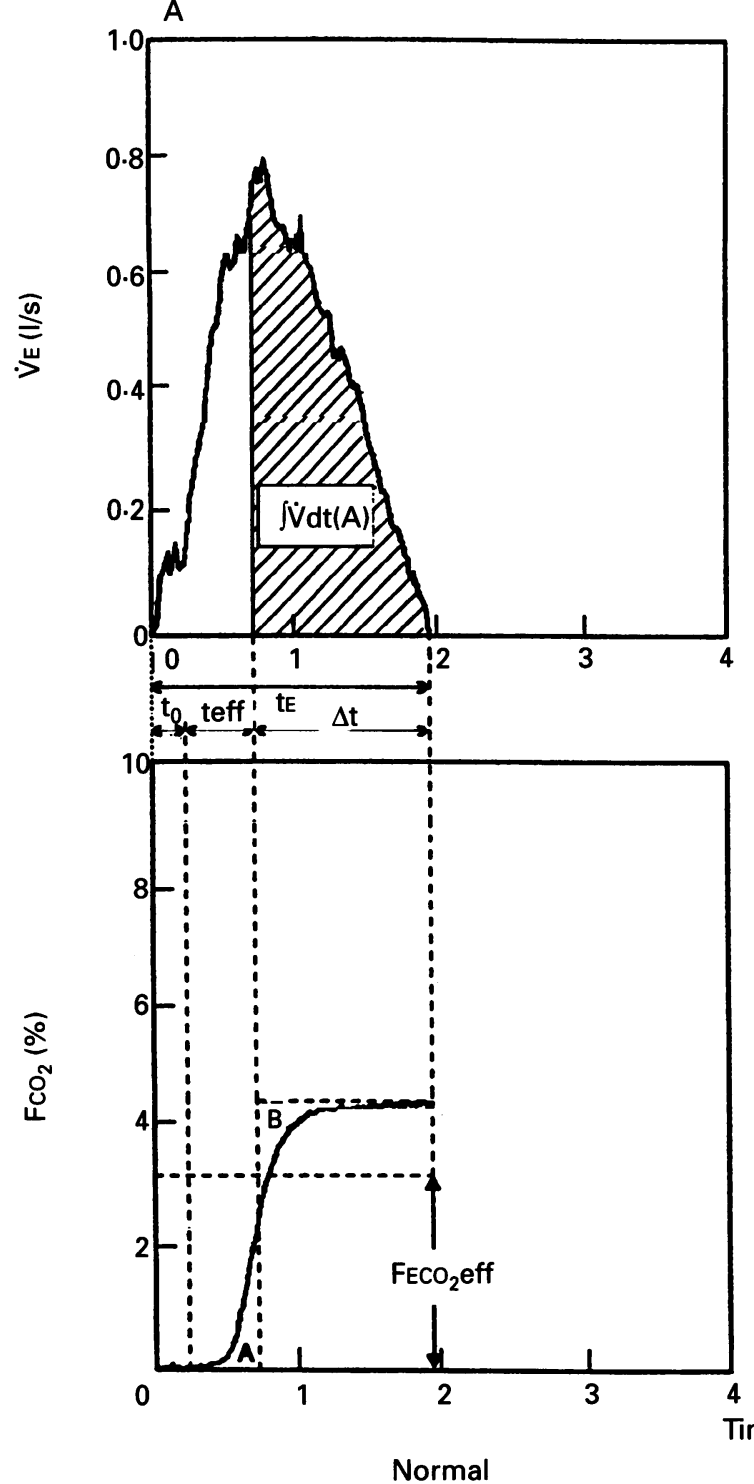

B

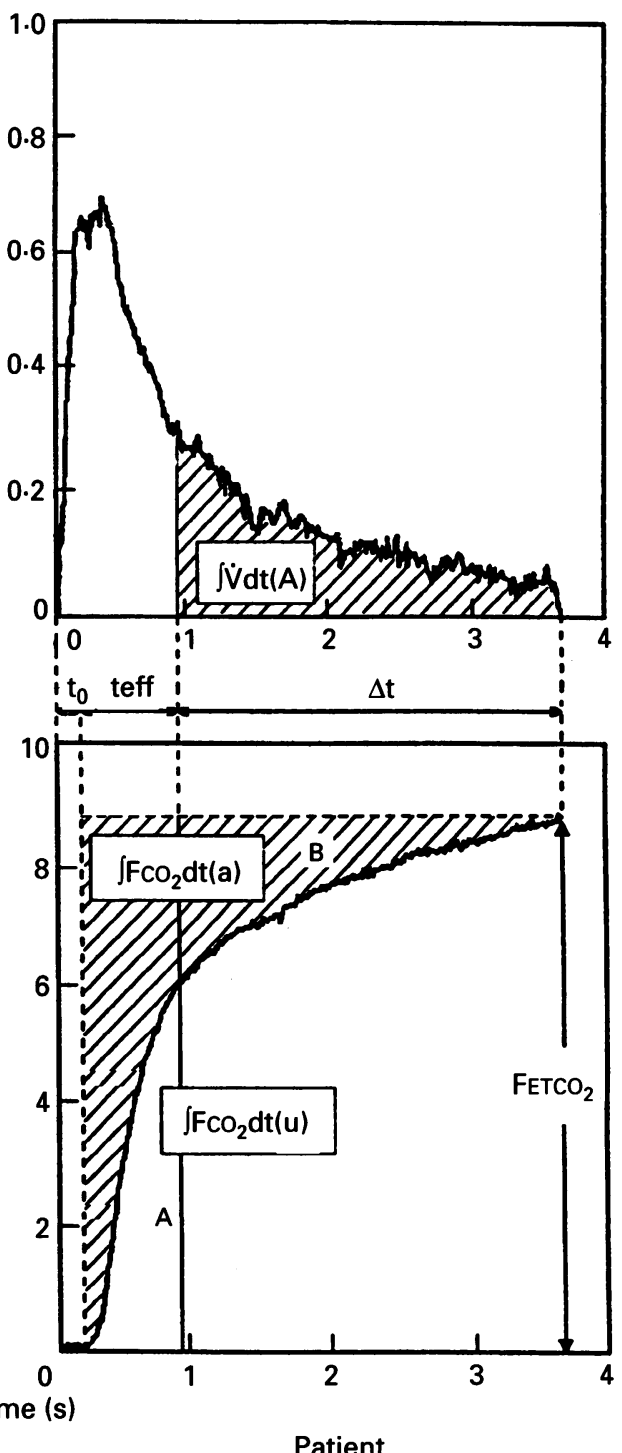

Figure 1 Expiratory flow $\left(\dot{V}_{E} / t\right)$ and $\mathrm{CO}_{2}$ concentration versus time curves $\left(\mathrm{FCO}_{2} / t\right)$ recorded simultaneously after correction for the phase lag during spontaneous breathing from $(A)$ a normal subject and $(B)$ a hypercapnic patient with $C O P D\left(V E\right.$ in $l / s, F_{C O}$ in \%, time in seconds). The expiratory time ( $\left.t E\right)$ is equal to the sum $\left(t_{0}+t e f f+\Delta t\right)$. In the $\mathrm{FCO}_{2} / t$ curves area $\mathrm{A}=$ area $B$ (see text). The area enclosed by the $\mathrm{FCO}_{2} / t$ curve $\left[\int \mathrm{FCO}_{2} d t(u)\right]=\left(\mathrm{FECO}_{2}\right.$ eff $\left.\times t E\right)$.

The effective time of the $\mathrm{FCO}_{2} / \mathrm{t}$ curve permits the transformation of this curve to a square wave, the initial part of which is characterised by $\left(\mathrm{t}_{0}+\right.$ teff $)$ and $\mathrm{FCO}_{2}=0$, and the rest of it by the time interval $\Delta \mathrm{t}=\left(\mathrm{tE}-\mathrm{t}_{0}-\right.$ teff $)$ and $\mathrm{FCO}_{2}=$ $\mathrm{FeTCO}_{2}$ (fig 1). In fact, $\Delta \mathrm{t}$ is equal to the ratio $\left[\int \mathrm{FCO}_{2} \mathrm{dt}(\mathrm{u}) / \mathrm{FETCO}_{2}\right]$ where $\int \mathrm{FCO}_{2} \mathrm{dt}(\mathrm{u})$ is the area enclosed by the curve itself, the time axis, and the vertical line passing through the point of $\mathrm{FETCO}_{2}$ (fig 1). The time interval $\left(\mathrm{t}_{0}+\right.$ teff) of the transformed $\mathrm{FCO}_{2} / \mathrm{t}$ curve corresponds to that part of the tidal volume (integrated area on $\dot{V} E / t$ curve) which does not participate in gas exchange $\left(\mathrm{FCO}_{2}=0\right)$ - that is, to the dead space volume [ $\int \dot{V} \mathrm{dt}(\mathrm{D})=\mathrm{VD}$ ] (fig 1 ). The rest of the tidal volume corresponds to the alveolar volume $\left[\int \dot{V} \operatorname{dt}(A)=V A\right]$ (fig 1$)$. The ratio of the area $\int \dot{V} \operatorname{dt}(A)$ divided by the area $\int \dot{V} d t(=V T)$ is the ratio of alveolar volume to tidal volume (VA/VT). The effective concentration of $\mathrm{CO}_{2}$ in the expired air $\left(\mathrm{FECO}_{2} \mathrm{eff}\right)$ per breath is equal to the ratio of the area $\int \mathrm{FCO}_{2} \mathrm{dt}(\mathrm{u})$ divided by the expiratory time (tE) (fig 1):

$$
\mathrm{FECO}_{2} \mathrm{eff}=\int \mathrm{FCO}_{2} \mathrm{dt}(\mathrm{u}) / \mathrm{tE}
$$

According to Bohr's equation the ratio $\mathrm{VA}$ $\mathrm{VT}$ is equal to the ratio $\mathrm{FECO}_{2} / \mathrm{FACO}_{2}$. Hence, the effective value of the alveolar $\mathrm{CO}_{2}$ concentration $\left(\mathrm{FACO}_{2} \mathrm{eff}\right)$ is equal to:

$$
\mathrm{FACO}_{2} \mathrm{eff}=\mathrm{FECO}_{2} \mathrm{eff} /(\mathrm{VA} / \mathrm{VT})
$$

\section{STUDY DESIGN}

The study was performed in 20 normal subjects (11 men) aged 18-65 (mean 40) years and 46 ambulatory patients ( 31 men) aged $35-83$ (mean 61) years with chronic bronchitis/emphysema or bronchial asthma. All patients were in a stable clinical and functional state and were recruited from the respiratory outpatient clinic. Their lung function data (table 1) were obtained in the seated position with a flowsensing spirometer (Fukuda; Spiroanalyzer ST300, Japan). Predicted lung function values were those of Morris and coworkers. ${ }^{18}$ Arterial 
Table 1 Mean (SD) spirmetric characteristics of the subjects studied (Fukuda Spiroanalyzer ST300)

\begin{tabular}{|c|c|c|c|c|c|c|c|}
\hline & \multicolumn{2}{|l|}{$F V C$} & \multicolumn{2}{|l|}{$F E V_{1}$} & \multirow{2}{*}{$\begin{array}{l}F E V_{I} / F V C \\
(\%)\end{array}$} & \multicolumn{2}{|l|}{$F E F_{25-75}$} \\
\hline & $l$ (BTPS) & $\%$ pred & $l$ (BTPS) & $\%$ pred & & $l / s$ & $\%$ pred \\
\hline $\begin{array}{l}\text { Normal subjects }(n=20) \\
\text { Patients }(n=46)\end{array}$ & $\begin{array}{l}3.995(0.986) \\
2.685(1.028)\end{array}$ & $\begin{array}{r}101 \cdot 01(10 \cdot 56) \\
69 \cdot 84(21.08)\end{array}$ & $\begin{array}{l}3 \cdot 211(0 \cdot 950) \\
1 \cdot 708(0 \cdot 898)\end{array}$ & $\begin{array}{l}97.67(8.72) \\
55.85(25 \cdot 03)\end{array}$ & $\begin{array}{l}79 \cdot 44(6 \cdot 40) \\
62 \cdot 18(17 \cdot 13)\end{array}$ & $\begin{array}{l}3.029(1.397) \\
1.205(1.041)\end{array}$ & $\begin{array}{l}87 \cdot 27(23 \cdot 07) \\
36 \cdot 15(28 \cdot 23)\end{array}$ \\
\hline
\end{tabular}

Normal predicted values obtained from Morris et al. ${ }^{18}$

$\mathrm{PCO}_{2}$ was measured with a blood gas analyser (ABL; Radiometer, Copenhagen, Denmark).

The experimental setup used to assess $\mathrm{PACO}_{2}$ was a flanged plastic mouthpiece connected in series to a Fleisch No 2 flow transducer head (Fleisch, Lausanne, Switzerland) via a metal piece (monitoring ring) on which the $\mathrm{CO}_{2}$ probe was attached. The pneumotachograph (transducer + amplifier: Gould Godart BV; No. 17212, Bilthoven, Holland) was connected with the Fleisch head via two semirigid plastic tubes, $12 \mathrm{~cm}$ in length. The pneumotachograph system (rise time $10-90 \%=13 \mathrm{~ms}$ ) was linear over the range of flows used. An infrared capnograph (Jaeger; $\mathrm{CO}_{2}$ test III, Wuerzburg, Germany) (rise time $10-90 \%=100 \mathrm{~ms}$ ) was connected to the monitoring ring through a thin polyethene tube $(50 \mathrm{~cm}$ length, internal diameter $1.2 \mathrm{~mm}$ ). The mouthpiece assembly had an expiratory dead space of less than $5 \mathrm{ml}$ and minimal resistance to airflow. Calibration of the capnograph was made using a mixture of $4 \% \mathrm{CO}_{2}$ in air before and after each study. The phase lag between the $\dot{\mathrm{V}} / \mathrm{t}$ and $\mathrm{FCO}_{2} / \mathrm{t}$ curves was determined by an abrupt change in flow of a gas mixture containing $4 \% \mathrm{CO}_{2}$ generated through the mouthpiece assembly.

The measurement of the phase lag and the calibration of the capnograph were repeated three times and the mean values used. The rise time $(10-90 \%)$ of the capnograph was at least 4.55 times faster than that of the fastest $\mathrm{FCO}_{2} / \mathrm{t}$ curve in normal subjects and in patients breathing at a respiratory frequency of 12-18/ min. ${ }^{1920}$ Airflow and $\mathrm{CO}_{2}$ signals were amplified, monitored on line on the computer screen, and sampled simultaneously at a rate of $75 \mathrm{~Hz}$ using a computer data acquisition system with a built in 12-bit analogue to digital converter (National Instruments; AT-M10, Austin, Texas, USA). Collected data were

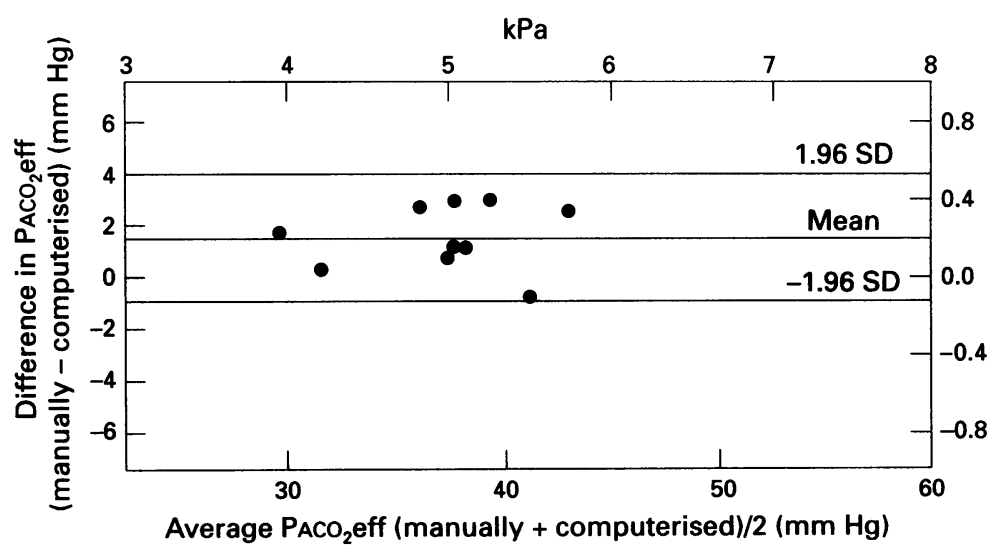

Figure 2 Bland-Altman diagram for the comparison between $\mathrm{PACO}_{2}$ eff calculated manually and $\mathrm{PACO}_{2}$ eff measured by computer. Upper limit of agreement (mean +1.96 $S D)=0.530 \mathrm{kPa}$; lower limit of agreement (mean $-1.96 \mathrm{SD})=-0.122 \mathrm{kPa}$. stored on computer disk for subsequent analysis with our custom made computer analysis software. These signals were also amplified (Hewlett-Packard; 7700 system, Waltham, Massachusetts, USA) and simultaneously recorded by a pen recorder (Hewlett-Packard; system 7700) onto thermographic paper with the speed of $20 \mathrm{~mm} / \mathrm{s}$. End tidal $\mathrm{CO}_{2}$ concentration $\left(\mathrm{FETCO}_{2}\right)$ was measured at the point on the $\mathrm{FCO}_{2} / \mathrm{t}$ curve corresponding to $\dot{\mathrm{V}}=$ 0. Alveolar $\mathrm{CO}_{2}$ tension was also computed manually from the $\dot{\mathrm{V}} \mathrm{E} / \mathrm{t}$ and $\mathrm{FCO}_{2} / \mathrm{t}$ curves recorded onto the thermographic paper according to equation (3) in order to check the validity of our custom made software computer program. The areas under the $\dot{V} E / t$ and $\mathrm{FCO}_{2} / \mathrm{t}$ curves were measured with a digital planimeter (Hewlett-Packard; 9111A Graphics Tablet) and a desk top calculator (Hewlett-Packard; $85 \mathrm{~A}$ ). The results obtained by manual and computer analysis in 10 normal subjects were related to each other by the Bland and Altman statistical method $^{12}$ (fig 2). It is evident that both methods of computation yielded closely similar results.

Subjects were studied while seated upright in a comfortable chair at least two hours after eating or taking coffee. They were asked to breathe room air through the equipment assembly while wearing a noseclip. Each subject had an initial 10-15 minute trial run to become accustomed to the apparatus and procedure. The pneumotachograph and the capnograph were continuously monitored on line on the computer screen. After regular breathing had been achieved a series of breaths was recorded over a period of one minute. At the end of the recording time an arterial blood sample $(>1 \mathrm{ml})$ was taken for gas analysis. A quick (5-10 second) and direct puncture of the brachial artery was performed by an expert doctor using a $21 \mathrm{G}$ needle.

The study was approved by the local ethics committee and all subjects gave informed consent.

\section{Results}

The effective alveolar $\mathrm{PCO}_{2}\left(\mathrm{PACO}_{2}\right.$ eff $)$ value for each individual is the mean $\mathrm{PACO}_{2}$ eff obtained

$\frac{0}{x}$ from all breaths during the one minute data collection period. In normal subjects the mean coefficient of variation (CV) of $\mathrm{PACO}_{2}$ eff was $6.0 \%$ (range $4 \cdot 1-9.9$ ) and in patients was $7.9 \%$ (range 2.4-23.0) within one study session.

The reproducibility of the method for assessing $\mathrm{PACO}_{2}$ eff was checked in terms of $\mathrm{CV}$ in three normal subjects in whom measurements were repeated three times per day for three consecutive days. Within day $\mathrm{CV}$ was $5 \cdot 7 \%$ (range $4 \cdot 2-7 \cdot 4$ ) and day to day CV was $5 \cdot 8 \%$ 
Table 2 Limits of agreement of $\mathrm{PACO}_{2}$ eff versus $\mathrm{PaCO}_{2}$

\begin{tabular}{|c|c|c|}
\hline & \multicolumn{2}{|c|}{$\mathrm{PACO}_{2}$ eff- $\mathrm{PaCO}_{2}(\mathrm{kPa})$} \\
\hline & $\begin{array}{l}\text { Normal subjects } \\
(n=20)\end{array}$ & $\begin{array}{l}\text { Patients } \\
(n=46)\end{array}$ \\
\hline Mean (SD) of the differences & $-0.205(0.373)$ & $-0.460(0.832)$ \\
\hline $\begin{array}{l}\text { Limits of agreement } \\
\text { Upper } \\
\text { Lower } \\
95 \% \text { confidence interval of the bias }\end{array}$ & $\begin{array}{l}0.526 \\
-0.935 \\
-0.029 \text { to }-0.379\end{array}$ & $\begin{array}{l}1 \cdot 170 \\
-2 \cdot 088 \\
-0 \cdot 213 \text { to }-0 \cdot 707\end{array}$ \\
\hline
\end{tabular}

(range 3.7-10.1). It is evident that the CV of $\mathrm{PACO}_{2}$ eff within and between days was practically the same as the $\mathrm{CV}$ of $\mathrm{PACO}_{2}$ eff for the group of normal subjects.

Among the normal subjects the mean (SD) $\mathrm{PACO}_{2}$ eff was $4.75(0.59) \mathrm{kPa}$ and $\mathrm{PaCO}_{2}$ was $4.96(0.45)$ (Student's paired $t$ test: $\mathrm{t}=-2.46$, $\mathrm{p}<0.05, \mathrm{n}=20$ ). In patients $\mathrm{PACO}_{2}$ eff was $5 \cdot 11(1.92) \mathrm{kPa}$ and $\mathrm{PaCO}_{2}$ was $5.57(1.48)(\mathrm{t}=$ $3 \cdot 75, \mathrm{p}<0 \cdot 001, \mathrm{n}=46)$. The variability around the mean of $\mathrm{PACO}_{2}$ eff and $\mathrm{PaCO}_{2}$ was greater in patients than in normal subjects. Regression analysis showed a significant linear relation between $\mathrm{PACO}_{2}$ eff and $\mathrm{PaCO}_{2}$. In normal subjects this relation was $\mathrm{PACO}_{2} \mathrm{eff}=-0.081+$ $0.129 \mathrm{PaCO}_{2} \mathrm{kPa}(r=0.77, \mathrm{SEE}=0.383 \mathrm{kPa}$, $\mathrm{p}<0.001)$ and in patients $\mathrm{PACO}_{2} \mathrm{eff}=-1.538+$ $0.159 \mathrm{PaCO}_{2} \mathrm{kPa} \quad(r=0.91, \quad \mathrm{SEE}=0.792$, $\mathrm{p}<0.001)$. The limits of agreement of $\mathrm{PACO}_{2} \mathrm{eff}$ versus $\mathrm{PaCO}_{2}$ were analysed by the method of Bland and Altman ${ }^{12}$ (table 2, figs 3 and 4).

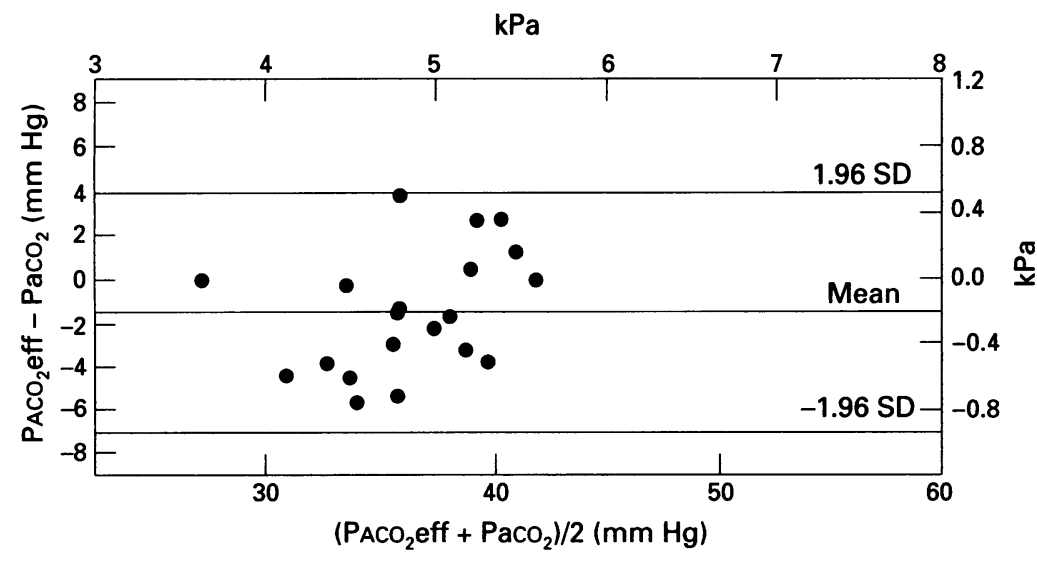

Figure 3 Comparison of $\mathrm{PACO}_{2}$ eff with $\mathrm{PaCO}_{2}$ by the Bland-Altman method in 20 normal subjects (see also table 2). Upper limit of agreement (mean $1.96 \mathrm{SD})=$ $0.526 \mathrm{kPa}$; lower limit of agreement (mean $-1.96 \mathrm{SD})=-0.935 \mathrm{kPa}$.

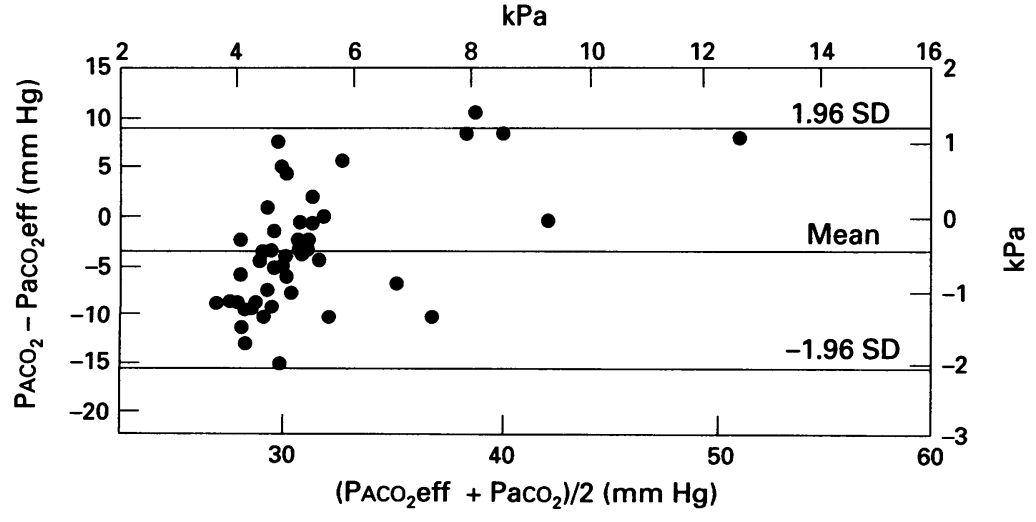

Figure 4 Comparison of $\mathrm{PACO}_{2}$ eff with $\mathrm{PaCO}_{2}$ by the Bland-Altman method in 46 patients with COPD (see also table 2). Upper limit of agreement (mean $+1.96 \mathrm{SD})=1.170 \mathrm{kPa}$ lower limit of agreement (mean-1.96 SD) $=-2.088 \mathrm{kPa}$.
The mean of the difference $\left(\mathrm{PACO}_{2} \mathrm{eff}-\right.$ $\mathrm{PaCO}_{2}$ ) and the range of limits of agreement were almost double in the patients compared with the normal subjects.

The end tidal $\mathrm{PCO}_{2}\left(\mathrm{PETCO}_{2}\right)$ was lower than the effective alveolar $\mathrm{PCO}_{2}$. In normal subjects the mean (SD) difference $\left(\mathrm{PACO}_{2}\right.$ eff $\left.-\mathrm{PETCO}_{2}\right)$ was $0.427(0 \cdot 300) \mathrm{kPa}(\mathrm{n}=20)$.

The mean (SD) of the $\mathrm{VD} / \mathrm{VT}$ ratio measured with our method in the normal subjects was $0.403(0.070)(n=20)$ and in the patients 0.478 $(0.082)(\mathrm{n}=46),(\mathrm{t}=-3.58, \mathrm{p}<0.001)$, while this ratio measured from $\mathrm{PECO}_{2}$ eff and $\mathrm{PaCO}_{2}$ was $0.433(0.082)$ in normal subjects $(n=20)$ and $0.536(0.079)$ in patients $(n=46),(t=$ $-5 \cdot 20, \mathrm{p}<0 \cdot 001)$.

\section{Discussion}

The effective $\mathrm{CO}_{2}$ concentration in the expirate $\left(\mathrm{FECO}_{2} \mathrm{eff}\right)$ is a weighted mean value between zero and $\mathrm{FETCO}_{2}$ according to equation (2). In order to separate the physiological dead space from the alveolar volume for the application of Bohr's equation the $\mathrm{FCO}_{2} / \mathrm{t}$ curve was transformed to a square wave by using the effective time of this curve. ${ }^{1314}$ In this way the ideal $\mathrm{CO}_{2}$ front with respect to time within the airways may be located at the end point of the time interval $\left(\mathrm{t}_{0}+\right.$ teff).

This principle for measuring the dead space volume is similar to that for the estimation of the so called "anatomical dead space volume". ${ }^{1314}$ The difference between our method and the earlier one is the simple mathematical approach for the determination of the effective time, as opposed to the geometrical approach with the declining plateau used in the past. Furthermore, the use of the $\mathrm{CO}_{2}$ concentration versus volume curve for the estimation of the $\mathrm{VD} / \mathrm{VT}$ ratio is not correct since, in this case, $\mathrm{PACO}_{2}$ has to be equal to $\mathrm{PeTCO}_{2}$.

In normal subjects the values of the $\mathrm{VD} / \mathrm{VT}$ ratio computed by our method are greater than those obtained by the old methods because the line of backwards extrapolation of the last part of the real $\mathrm{FCO}_{2} / \mathrm{t}$ curve is not parallel to the time axis, resulting in a smaller area than $\int \mathrm{FCO}_{2} \mathrm{dt}(\mathrm{a})$ and so to a smaller $\mathrm{VD} / \mathrm{VT}$ ratio.

The effective alveolar $\mathrm{CO}_{2}$ concentration $\left(\mathrm{FACO}_{2} \mathrm{eff}\right)$ is computed from $\mathrm{FECO}_{2} \mathrm{eff}$ and the $\mathrm{VA} / \mathrm{VT}$ ratio, and so is liable to errors inherent in the measurement of the areas of the $\mathrm{FCO}_{2} / \mathrm{t}$ and of the $\dot{V} E / t$ curves. However, such errors must be small since the dispersion of $\mathrm{PACO}_{2}$ eff around the mean for each individual was small in all normal subjects.

The mean coefficient of variation for $\mathrm{PACO}_{2}$ eff, which reflects the precision of the measurement, was $6 \%$ (range $4 \cdot 1-9.9 \%$ ) in normal subjects and $2 \cdot 4-23.0 \%$ in patients. This finding may be explained by the wide range of time constants within the lungs of the patients, or by the breath by breath variation of their VE/t curves, or both. ${ }^{15} 17$

The regression equations showed a strong relation between $\mathrm{PACO}_{2}$ eff and $\mathrm{PaCO}_{2}$ in both normal subjects and patients. There were highly significant differences between $\mathrm{PACO}_{2}$ eff and $\mathrm{PaCO}_{2}$ both in patients and normal subjects. 
The difference $\left(\mathrm{PACO}_{2}\right.$ eff $\left.-\mathrm{PaCO}_{2}\right)$ was close to that obtained using the two stage helium washout technique. ${ }^{21}$

We conclude that (1) effective alveolar $\mathrm{PCO}_{2}$ $\left(\mathrm{PACO}_{2} \mathrm{eff}\right)$ can be estimated simply in the laboratory or at the bedside without any special manoeuvre on the part of the subject. The subject breathes freely without any appreciable resistance through the mouthpiece assembly which has no two way valve; (2) $\mathrm{PACO}_{2}$ eff is significantly different from $\mathrm{PaCO}_{2}$ in both normal subjects and patients, but in normal subjects the difference between the alveolar and arterial $\mathrm{CO}_{2}$ tension is relatively smaller; and (3) this estimate of $\mathrm{PACO}_{2}$ eff should be used in the theoretical calculation of dead space and $\mathrm{CO}_{2}$ shunt.

We are grateful to Professor J Milic-Emili for constructive criticisms and the "ARMADA" Company, Attica, Greece for the development of the computer software.

1 Sykes MK, McNicol MW, Campbell EJM, eds. Respiratory Sykes MK, McNicol MW, Campbell EJM, eds. Respiratory failure.

2 Engel LA. Intraregional gas mixing and distribution. In: Engel LA, Paiva M, eds. Gas mixing and distribution in the lung. New York: Marcel Dekker, 1985:326-7.

3 Enghoff $\mathrm{H}$. Volumen inefficax, bemer Kungen zur Frage des schadlichen Raumes. Ups Lakaref 1938;44:191-218.

4 Boyhus A. Respiratory dead space. In: Fenn WO, Rahn H, eds. Respiration. American Physiological Society, 1964: 699-714.

5 Asmussen E, Nielsen M. Physiological dead-space and alveolar gas pressures at rest and during muscular exercise. Acta Physiol Scand 1956;38:1-21.

6 Otis AB. Quantitative relationships in steady-state gas exchange. In: Fenn WO, Rahn H, eds. Respiration. American Physiological Society, 1964:681-98.
7 Anthonisen NR, Fleetmann JA. Ventilation: total, alveolar, and dead space. In: Fishman AP, Fahri LE, Tenney RM Geigen SR, eds. Handbook of physiology. The respiratory system. American Physiological Society, 1987:113-29.

8 Hlastala MP. Ventilation. In: Crystal RG, West JB, Barnes PJ, Cherniack NS, Weibel ER, eds. The lung. 1st edn New York: Raven Press, 1991:1211-3.

9 Cerretelli P, di Prampero PE. Pulmonary gas exchange. In: Crystal RG, West JB, Barnes PJ, Cherniack NS, Weibel ER, eds. The lung J, Barnes PJ, Cherniack NS, Weibel ER, ed.

10 Riley RL, Lilienthal JL, Proemmel DD, Franke RE. On the determination of the physiologically effective pressures of oxygen and carbon dioxide in alveolar air. Am $\mathcal{F}$ Physiol 1946;147:191-8.

11 Luft UC, Loeppky JA, Mostyn EM. Mean alveolar gases and alveolar-arterial gradients in pulmonary patients. $\mathcal{F}$ Appl Physiol 1979;46:534-40.

12 Bland JM, Altman DG. Statistical methods for assessing agreement between two methods of clinical measurement. agreement between two
Lancet $1986 ; \mathrm{i}: 307-10$.

13 Fowler WS. Lung function studies II. The respiratory deadspace. Am f Physiol 1948;154:405-16.

14 Fowler WS. Lung function studies III. Uneven pulmonary ventilation in normal subjects and in patients with pulmonary disease. F Appl Physiol 1949;2:283-99.

15 Hugh-Jones P, Barter CE, Hime JM, Rusbridge MM. Dead space and tidal volume of the giraffe compared with some other mammals. Respir Physiol 1978;35:53-8.

16 Bouhuys A. Distribution of inspired gas in the lung. In: Fenn WO, Rahn H, eds. Respiration. American Physiological Society, 1964:715-33.

17 Sanchis J, Diez-Betoret JL, Canet J, Casan P. Pneumotachographic recording of ventilatory pattern. In: Benito $\mathrm{S}$, Net A, eds. Pulmonary function in mechanical ventilated patients. New York: Springer-Verlag, 1991:9-22.

18 Morris AH, Kanner RE, Crapo RO, Gardner RM. Clinical pulmonary function testing: a manual of uniform laboratory procedures. 2nd edn. Salt Lake City: Intermountain Thoracic Society, 1984.

19 Shykoff BE, Swanson HT. A model-free method for mass spectrometer response correction. $¥$ Appl Physiol 1987;63: spectrometer

20 Clayton GB. Understanding operational amplifier performance parameters. In: Clayton GB, ed. Operational amplifiers. 2nd edn. London: Butterworths, 1979:16-99.

21 Jordanoglou J, Tatsis G, Danos J, Gougoulakis S, Orfanidou D, Gaga M. Alveolar partial pressures of carbon dioxide and oxygen measured by a helium washout technique. Thorax 1990;45:520-4. 